\title{
Editorial
}

\section{A Revista Brasileira de Cardiologia Invasiva em Perspectiva}

D esde o início de sua publicação, há 15 anos, a Revista Brasileira de Cardiologia Invasiva ( $\mathrm{RBCl}$ ) submeteu-se a mudanças no conteúdo, periodicidade e tiragem, refletindo o crescimento da Cardiologia Intervencionista brasileira.

Aplaudimos o trabalho dos editores que nos antecederam, que trouxeram diferentes contribuições e levaram a RBCl à atual posição. Em especial, reconhecemos o trabalho excepcional do Dr. Adriano Caixeta, cujo mandato como editor-chefe ora se encerra, auxiliado pelos co-editores, Drs. Luiz Alberto Piva e Mattos e Pedro Alves Lemos Neto, e pela assessora editorial, Rosangela Monteiro. Durante a sua gestão, atrasos na distribuição da revista foram resolvidos, a submissão de artigos originais aumentada e novas seções foram incorporadas. Neste período, a programação visual e apresentação gráfica foram melhoradas, fazendo com que a revista se tornasse visualmente mais atrativa. $\mathrm{O}$ número de revistas impressas foi aumentado e a distribuição inclui, na atualidade, todos os cardiologistas cadastrados na Sociedade Brasileira de Cardiologia e na $\mathrm{SBHCl}$, além de centenas de bibliotecas e instituições do País, totalizando mais de $11 \mathrm{mil}$ exemplares. Todos esses avanços foram coroados com a indexação da $\mathrm{RBCl}$ na base de dados LILACS (Literatura Latino-Americana e do Caribe em Ciências da Saúde), em janeiro de 2007.

Estamos conscientes que assumimos a função de editora em um momento de crescimento e expansão da $\mathrm{RBCl}$ e agradecemos à diretoria da $\mathrm{SBHCl}$ pela confiança depositada. Dedicaremos todos os nossos esforços para consolidar essa posição e, ao mesmo tempo, perseguir novas metas. Essas metas compreendem a internacionalização do jornal, a divulgação em países da América Latina e a indexação na base de dados do MEDLINE. Lembramos que a RBCl é, na atualidade, o único jornal latino-americano especializado em Cardiologia Intervencionista e, como tal, tem grande potencial para crescer, captando artigos de colegas proeminentes desses países. Indexado no MEDLINE, integrará o grupo seleto de jornais especializados como o Catheterization and Cardiovascular Interventions e o Eurolntervention, entre outros.

Algumas medidas para atingir essas metas já estão sendo tomadas, como a inclusão da versão do jornal em inglês na página eletrônica da SBCHI; a divulgação, por correio eletrônico, do conteúdo das edições para todos os membros da SOLACl; a agilização do processo editorial, com a recente ampliação em mais de 50\% do Conselho de Revisores e a otimização da gestão de artigos, por meio do sistema eletrônico (SGP); o pedido de indexação no SciELO, etapa importante para alcançarmos o MEDLINE. Merece especial citação a atuação da $\mathrm{SBHCl}$ na captação de artigos originais de relevante valor científico, ao estabelecer prêmios para os 10 melhores temas-livres - categoria oral e o melhor temalivre - categoria pôster, submetidos ao próximo Congresso da $\mathrm{SBHCl}$ e que serão posteriormente publicados na RBCl. Estamos planejando, também, para as próximas semanas, a atualização das normas de publicação da $\mathrm{RBCl}$, com a finalidade de adaptá-las aos requerimentos do Comitê Internacional de Editores de Revistas Médicas.

Finalizando, gostaríamos de ressaltar a contribuição fundamental de autores e revisores, que levaram a $\mathrm{RBCl}$ a alcançar o patamar em que atualmente se encontra. Essa posição é também fruto de estratégias editoriais cuidadosamente planejadas e o suporte incondicional de toda a diretoria da $\mathrm{SBHCl}$, em especial de seu Presidente Dr. Luiz Alberto Piva e Mattos e de seu Diretor de Comunicações Dr. Rogério Eduardo Gomes Sarmento-Leite.
Áurea Jacob Chaves
Editora, Revista Brasileira de Cardiologia Invasiva 